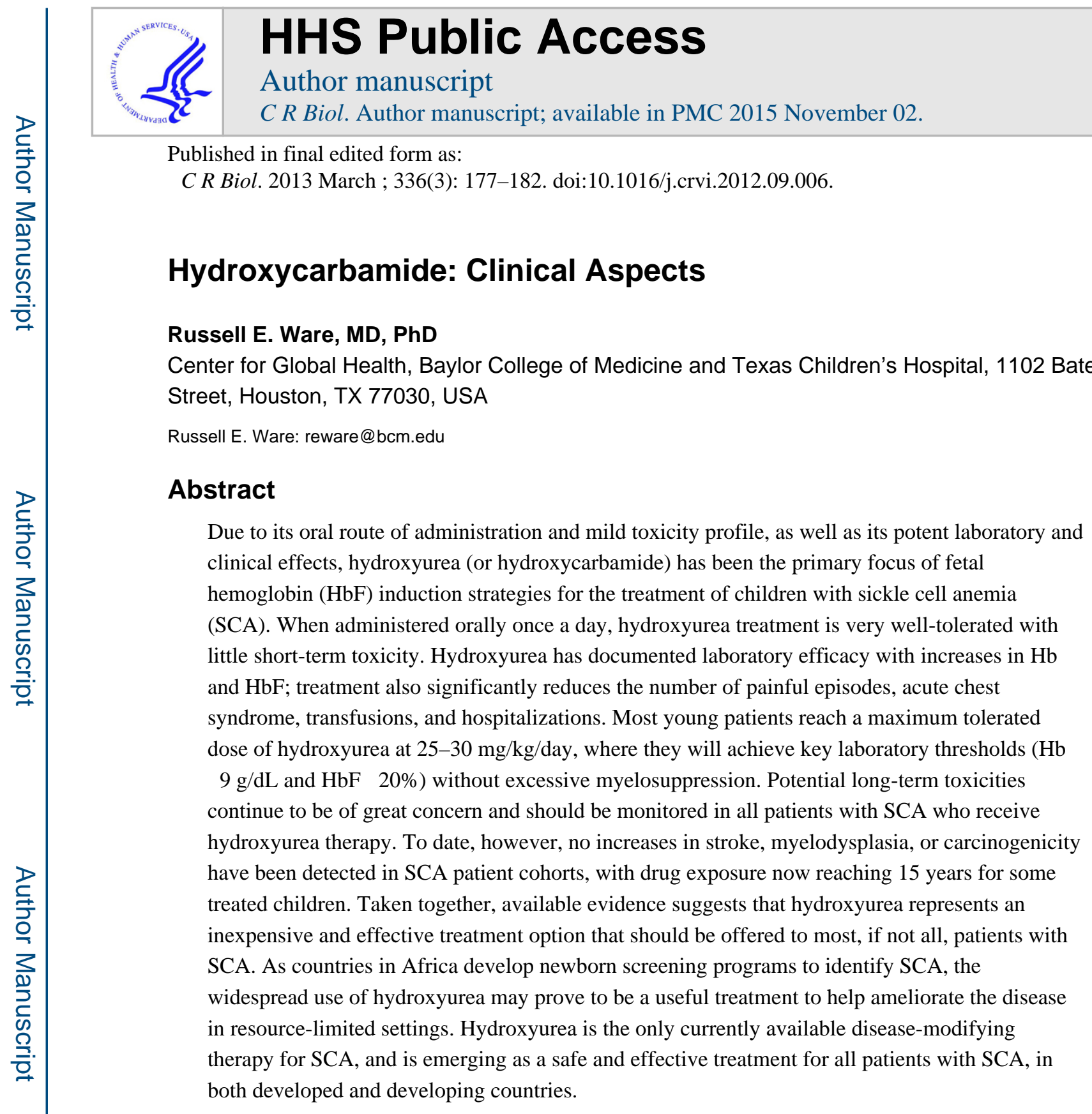

\title{
Introduction
}

Pharmacological induction of fetal hemoglobin $(\mathrm{HbF})$ as a potential therapeutic strategy for sickle cell anemia (SCA) arises from two key observations regarding the benefits of elevated HbF levels: (1) persons who co-inherit hereditary persistence of fetal hemoglobin with SCA have minimal or no clinical manifestations, and (2) infants with SCA have few clinical manifestations in the first 3-6 months of life. The HbF level in SCA is protective but declines rapidly during the first year of life and eventually reaches a nadir around age 5

Publisher's Disclaimer: This is a PDF file of an unedited manuscript that has been accepted for publication. As a service to our customers we are providing this early version of the manuscript. The manuscript will undergo copyediting, typesetting, and review of the resulting proof before it is published in its final citable form. Please note that during the production process errors may be discovered which could affect the content, and all legal disclaimers that apply to the journal pertain. 
years [1,2]; this latter value, often referred to as the "baseline" $\mathrm{HbF}$ value for individual patients, is strongly influenced by genetic factors $[3,4]$ but still is not completely understood.

The biophysical basis for protection by $\mathrm{HbF}$ against sickling is primarily on the basis of reducing the rate of $\mathrm{HbS}$ polymerization within the erythrocytes. $\mathrm{HbF}$ tetramers dilute the intracellular $\mathrm{HbS}$ concentration and do not participate in the polymerization process. Based on these observations, efforts were made to identify therapeutic agents that could induce $\mathrm{HbF}$, and hydroxyurea emerged as one of several effective compounds. Due to its oral route of administration and known toxicity profile, as well as its potent laboratory and clinical effects, hydroxyurea has been the primary focus of $\mathrm{HbF}$ induction strategies for SCA to date.

In the 1980's, fairly simple but elegant "proof-of-principle" studies demonstrated the potential benefits of hydroxyurea (or hydroxycarbamide) therapy for adults with SCA [5]. Following short-term high-dose oral pulses of hydroxyurea, reticulocytes with increased fetal hemoglobin $(\mathrm{HbF})$ were observed in the peripheral circulation, followed by an increased overall hemoglobin concentration and increased $\% \mathrm{HbF}$, documenting the ability of hydroxyurea to induce $\mathrm{HbF}$ production. Now almost 30 years later, we have accumulated a large amount of research data and clinical experience regarding the use of hydroxyurea in this patient population [6]. Hydroxyurea is currently recognized as a potent pharmacological agent for $\mathrm{HbF}$ induction, with proven laboratory and clinical efficacy for infants, children, adolescents, teens, and adults with SCA. HbF induction is the primary therapeutic effect of hydroxyurea in SCA. However, additional treatment benefits are derived including mild myelosuppression, macrocytosis, reduced cellular adhesion, improved rheology, and potentially local nitric oxide release [6].

\section{Treatment indications}

Clinical recommendations for when to consider hydroxyurea therapy are still evolving and consensus have guidelines not yet been established. Through a series of Phase I/II and Phase III clinical trials involving adults [7], school-age children [8], and even infants with SCA [9], hydroxyurea has documented laboratory efficacy and also significantly reduces the number of painful episodes (crises), acute chest syndrome (ACS) episodes, transfusions, and hospitalizations.

Based on efficacy data from these prospective clinical trials, frequent or severe painful vasoocclusive events and ACS are the most common reasons to consider hydroxyurea (Table 1). Other clinical indications that often lead to hydroxyurea therapy include dactylitis, severe anemia, elevated transcranial Doppler (TCD) velocities, poor growth, and frequent hospitalizations. Additional potential indications include preservation of organ function or even reversal of organ dysfunction; hence patients with hypoxemia, proteinuria, or cerebrovascular disease may initiate hydroxyurea as well. Some clinicians feel that a laboratory profile reflecting disease severity (e.g., elevated white blood cell count, low $\% \mathrm{HbF}$, high $\mathrm{LDH}$ ) also warrants consideration to initiate hydroxyurea. Ongoing and future research studies should clarify the role of hydroxyurea for these various indications. More recently, families are asking for hydroxyurea treatment, usually after one affected sibling is 
receiving therapy. In these settings, clinicians should consider the benefits of hydroxyurea for the otherwise "unselected" patient who has yet to develop clinical severity.

There is no ideal age to initiate therapy, but the safety profile of hydroxyurea has been documented in patients as young as $6-9$ months of age $[9,10]$. Younger patients tend to have better treatment responses and better medication adherence than older patients, hence a decision to begin therapy should be consider early in life, ideally before 5-10 years of age. However, clinical efficacy can be demonstrated at any time; as noted above, even adults with severe symptoms had significant reduction in pain, ACS, transfusion, and hospitalization when started on hydroxyurea therapy [7].

\section{Initiation and dose escalation}

Hydroxyurea can be administered orally as capsules or by an extemporaneously prepared liquid formulation, given once a day [11]. The starting dose in the United States is typically $15-20 \mathrm{mg} / \mathrm{kg} / \mathrm{day}$, which is tolerated by virtually all patients with SCA. Most investigators then monitor with monthly blood counts and escalate by $5 \mathrm{mg} / \mathrm{kg} /$ day every 8 weeks, to reach the maximum tolerated dose (MTD), typically defined as mild myelosuppression such as ANC of $2.0-4.0 \times 10^{9} / \mathrm{L}(2,000-4,000$ neutrophils $/ \mu \mathrm{L})$. However, myelosuppression to lower ANC values, e.g., 1.0-2.0 $\times 10^{9} / \mathrm{L}$ appears to be safe, and no episodes of bacteremia or serious infection have been reported due to drug-induced neutropenia. Reticulocytes are also affected by hydroxyurea, and up to $25 \%$ of patients will develop reticulocytopenia as the main dose-limiting toxicity.

Most young patients reach MTD at 25-30 mg/kg/day, and at that dose will achieve key laboratory thresholds (hemoglobin concentration $\geq 9 \mathrm{~g} / \mathrm{dL}$ and $\mathrm{HbF} \geq 20 \%$ ) without excessive myelosuppression. In Europe, clinicians often prefer a lower dose that can be termed the minimally effective dose (MED), typically $15-20 \mathrm{mg} / \mathrm{kg} / \mathrm{day}$, defined operationally as the dose where patients improve clinically and feel better. Compared to the MTD, patients who receive the MED tend to have lower treatment responses based on hemoglobin and $\mathrm{HbF}$ values [12].

Patients with renal dysfunction, low marrow reserve, or unusual body habitus (i.e., high body mass index) will not tolerate standard dose escalation and may have a low hydroxyurea MTD. In all patients, monthly monitoring is required initially to reach a safe and stable dose, whether MTD or MED, after which time the frequency of visits can be modified.

Medication adherence is an important part of hydroxyurea therapy, and efforts should be undertaken to ensure that patients and families understand the importance of daily dosing with good compliance. Strategies to improve medication adherence have been described [11].

\section{Treatment responses}

Patients and families should understand that the effects of hydroxyurea are not immediate. Laboratory changes occur over the first few weeks, typically with a rise in MCV and a concomitant fall in the ANC and absolute reticulocyte count (ARC). As the hydroxyurea dose is escalated toward MTD, changes also become evident in the peripheral blood smear: 
macrocytosis without polychromasia, fewer sickled forms, more target cells, and lower numbers of circulating neutrophil and reticulocytes. Figure 1 illustrates typical changes in the laboratory profile and peripheral blood smear of a young patient with SCA who initiates hydroxyurea with dose escalation to MTD. Beneficial effects on $\% \mathrm{HbF}$ are not necessarily evident early in treatment, reaching maximum effects only after 6-12 months of treatment [8].

At each visit, compliance and especially medication adherence must be emphasized. Each missed daily dose allows erythropoiesis to occur without the "influence" of hydroxyurea, so represents a missed opportunity to ameliorate the disease. Responses are sustained as long as adherence is maintained. Downward trends in MCV and $\mathrm{HbF}$, or upward trends in ANC and ARC, often reveal problems with adherence. Periodic review of the peripheral blood smear with the patient and family can be helpful in promoting adherence [11].

\section{Drug-related toxicities}

When administered orally once a day, hydroxyurea treatment is very well-tolerated with little short-term toxicity. Mild cytopenias, especially of granulocytes and reticulocytes, are expected and actually should be considered therapeutic goals of treatment. If cytopenias are ever excessive, counts recover quickly after a temporary treatment hold, typically one week. Patients typically require a complete blood count with reticulocytes every month during initial dose escalation, but monitoring can be reduced to every 2-3 months once a stable MTD is established. Mild gastrointestinal symptoms can occur but usually abate following adjustment of daily dosing, e.g., giving the dose before bedtime. Dermatological changes including melanonychia and hyperpigmentation do occur but are cosmetic only. Other toxicities such as hair loss, rash, skin ulcers, and hepatic or renal dysfunction are exceedingly rare, if they occur at all in this patient population.

\section{Previous Research}

Hydroxyurea research in SCA is now approaching 30-years of experience (Figure 2). In 1984 the first proof-of-principle study was reported [5], followed by prospective Phase I/II studies in adults [13], then children [8] and finally infants [10]. The landmark Phase III Multicenter Study of Hydroxyurea trial was published in 1995; this randomized placebocontrolled trial proved the clinical efficacy of hydroxyurea for the prevention of pain, ACS, transfusion, and hospitalization of adults with SCA [7].

Two major NIH-sponsored clinical trials involving hydroxyurea have been recently completed. In the Phase III infant hydroxyurea trial (BABY HUG, ClinicalTrials.gov NCT00006400), infants with SCA between 9-18 months old were recruited without regard to clinical severity, and randomized either to daily hydroxyurea $(20 \mathrm{mg} / \mathrm{kg} / \mathrm{day})$ or placebo for 24 months of treatment. Although the primary study endpoints (prevention of organ dysfunction) were not met, secondary study endpoints of reduced pain, dactylitis, acute chest syndrome, transfusions, and hospitalizations were all significantly lower in the hydroxyurea treatment arm [9]. Based on these findings, the authors concluded that hydroxyurea can now be considered for all young patients with SCA. 
A second major NIH-funded study was Stroke With Transfusions Changing to Hydroxyurea (SWiTCH, NCT00122980), which treated children with documented stroke and iron overload either with standard treatment (transfusions and chelation) or alternative treatment (hydroxyurea and phlebotomy) to prevent secondary stroke and better manage iron overload.

This study was stopped early due to a failure of the alternative treatment arm to improve iron overloading between phlebotomy and chelation; at the time of study closure there was a stroke imbalance of $10 \%$ on hydroxyurea versus $0 \%$ on transfusions [14]. Additional lessons learned from the SWiTCH trial include the severe vasculopathy and clinical fragility present among most children with SCA and previous stroke, and the difficulty of a composite primary study endpoint in a multicenter randomized clinical trial.

\section{Current Research}

Several NIH-funded clinical trials involving hydroxyurea for patients with SCA are currently underway. The first is TCD With Transfusions Changing to Hydroxyurea (TWiTCH, NCT01425307), where children with abnormal Transcranial Doppler velocities who receive chronic transfusions will be randomized either to standard treatment (continued transfusions) or alternative treatment (hydroxyurea). The primary endpoint is change in TCD velocity and this study is currently enrolling patients in the US and Canada. The second study is Sparing Conversion to Abnormal TCD Elevation (SCATE, NCT01531387), where children with conditional TCD velocities will be randomized either to standard treatment (observation) or alternative treatment (hydroxyurea) to prevent increases (conversion) to the abnormal threshold of $200 \mathrm{~cm} / \mathrm{sec}$. This study includes clinical sites in the US, Jamaica, and Brazil and patient enrollment is ongoing. The Hydroxyurea Study of Long-Term Effects (HUSTLE, NCT00305175) continues to gather information on the pharmacokinetics and pharmacogenetics of hydroxyurea treatment for children with SCA, as well as the long-term effects of hydroxyurea on organ function. Finally, the BABY HUG cohort is now being following prospectively in a follow-up study (NCT00890396), to help determine the long-term risks and benefits of hydroxyurea treatment when initiated at an early age.

\section{Long-term follow-up}

Potential long-term toxicities continue to be of great concern and should be monitored in all patients with SCA who receive hydroxyurea therapy. To date, no increase in stroke, myelodysplasia, or carcinogenicity has been detected in SCA patient cohorts, now reaching 15-20 years of exposure for some treated adults and 10-15 years for treated children.

Regarding the rare case reports of malignancy developing in patients on hydroxyurea, the background cancer rate in SCA must be considered [15] to prevent undue concern or illadvised associations. Deleterious effects of hydroxyurea on fertility are suggested but not proven, in particular the effects on sperm production. However, clinical experience suggests no effect on fertility of either men or women with SCA. Similarly, teratogenicity is a theoretical risk has not been observed clinically, but a recent report from an adult cohort is reassuring with respect to pregnancy outcomes [16]. While most clinicians still recommend avoidance of pregnancy or conception while receiving hydroxyurea therapy, limited data indicate no adverse effects. In the setting of a pregnant woman with SCA on hydroxyurea, 
the risks of continuing hydroxyurea must be weighed carefully against the risks of discontinuing an effective treatment in a high-risk pregnancy.

From the standpoint of long-term benefits, the profile of hydroxyurea therapy is encouraging. Numerous studies document sustained laboratory and clinical benefits for patients who remain adherent, with improved growth/development in young patients. Two recent long-term adult studies (USA and Greece) have documented improved survival of patients with SCA and hydroxyurea exposure [17,18]; improved mortality on hydroxyurea provides an even more compelling reason to consider treatment for all affected patients.

\section{Developing countries}

Despite the accumulated evidence for benefits of hydroxyurea in children with SCA of all ages, there are scant data regarding its use in developing countries where the burden is greatest [19]. With over 300,000 babies born with sickle cell disease worldwide each year, the opportunity to provide the only disease-modifying treatment should be a high priority. However, the safety and feasibility of hydroxyurea treatment in the setting of co-morbidities such as general malnutrition, vitamin and micronutrient deficiencies, and infections (malaria, helminthes) have not been assessed.

While it is tempting to consider hydroxyurea suitable for current use in developing countries, especially in Africa, a careful assessment of its risks and benefits is warranted, ideally through prospective studies such as the proposed Realizing Effectiveness Across Continents with Hydroxyurea (REACH) pilot trial. As countries in Africa develop newborn screening programs to identify SCA, the widespread use of hydroxyurea may prove to be a useful treatment to help ameliorate the disease in resource-limited settings.

\section{Knowledge gaps}

An important area of future investigation is to explain the observed phenotypic variability of the hydroxyurea response. The ability to tolerate different doses of hydroxyurea is variable among patients, as is the $\mathrm{HbF}$ response. Recent investigation has suggested that pharmacokinetic differences exist as well as pharmacogenetic influences [20].

Another critical knowledge gap exists because almost all of the available data relate to patients with SCA (i.e., $\mathrm{HbSS}$ or $\mathrm{HbS} / \beta^{0}$-thalassemia); experience with $\mathrm{HbSC}$ and $\mathrm{HbS} / \beta^{+}-$ thalassemia is limited to anecdotes and small series, and extrapolations to these patient populations should not be assumed. Prospective studies involving HbSC are badly needed, since clinicians are increasingly using hydroxyurea in this patient population. Although $\mathrm{HbF}$ does not have a clear benefit for patients with $\mathrm{HbSC}$, the additional salutary effects such as lower WBC and reduced cellular adhesion may provide therapeutic benefits. Measurements of blood viscosity may prove useful in clinical trials involving $\mathrm{HbSC}$ patients, since increases in the hemoglobin concentration from hydroxyurea are common and could potentially be deleterious. 


\section{Summary}

With almost 30 years of accumulated experience since the initial studies, we have ample documentation of the short-term safety and efficacy of hydroxyurea for patients with SCA. Long-term data are continuously accumulating and are to date equally reassuring. Taken together, the available evidence suggests that hydroxyurea represents an inexpensive and effective treatment option that should be offered to most, if not all, patients with SCA [21]. Current and future research will help define its role in the preservation of organ function. As the only currently available disease-modifying therapy for SCA, hydroxyurea may prove to be a safe and effective treatment for patients with SCA in both developed and developing countries.

\section{References}

1. Marcus SJ, Ware RE. Physiologic decline in fetal hemoglobin parameters in infants with sickle cell disease: implications for pharmacological intervention. J Pediatr Hematol/Oncol. 1999; 21(5):407411.

2. Brown AK, Sleeper LA, Miller ST, Pegelow CH, Gill FM, Waclawiw MA. Reference values and hematologic changes from birth to 5 years in patients with sickle cell disease. Cooperative Study of Sickle Cell Disease. Arch Pediatr Adolesc Med. 1994; 148(8):796-804. [PubMed: 7519102]

3. Powars D, Hiti A. Sickle cell anemia. Beta-S gene cluster haplotypes as genetic markers for severe disease expression. Am J Dis Child. 1993; 147(11):1197-1202. [PubMed: 8237915]

4. Lettre G, Sankaran VG, Bezerra MA, et al. DNA polymorphism at the BCL11A, HBS1L-MYB, and beta-globin loci associate with fetal hemoglobin levels and pain crises in sickle cell disease. Proc Natl Acad Sci USA. 2008; 105(33):11869-11874. [PubMed: 18667698]

5. Platt OS, Orkin SH, Dover G, Beardsley GP, Miller B, Nathan DG. Hydroxyurea enhances fetal hemoglobin production in sickle cell anemia. J Clin Invest. 1984; 74(2):652-656. [PubMed: 6205021]

6. Ware RE. How I use hydroxyurea to treat young patients with sickle cell anemia. Blood. 2010; 115(26):5300-5311. [PubMed: 20223921]

7. Charache S, Terrin ML, Moore RD, et al. Effect of hydroxyurea on the frequency of painful crises in sickle cell anemia: Investigators of the Multicenter Study of Hydroxyurea in Sickle Cell Anemia. N Engl J Med. 1995; 332(20):1317-1322. [PubMed: 7715639]

8. Kinney TR, Helms RW, O'Branski EE, et al. Safety of hydroxyurea in children with sickle cell anemia: results of the HUG-KIDS study, a phase I/II trial. Pediatric Hydroxyurea Group. Blood. 1999; 94(5):1550-1554. [PubMed: 10477679]

9. Wang WC, Ware RE, Miller ST, et al. Hydroxycarbamide in very young children with sickle-cell anaemia: a multicenter, randomized, controlled trial (BABY HUG). Lancet. 2011; 377(9778):16631672. [PubMed: 21571150]

10. Wang WC, Wynn LW, Rogers ZR, Scott JP, Lane PA, Ware RE. A two-year pilot trial of hydroxyurea in very young children with sickle-cell anemia. J Pediatr. 2001; 139(6):790-796. [PubMed: 11743503]

11. Heeney MM, Ware RE. Hydroxyurea for children with sickle cell disease. Pediatr Clin North Am. 2008; 55(2):483-501. [PubMed: 18381097]

12. Ware RE, Aygun B. Advances in the use of hydroxyurea. Am Soc Hematol Educ Program. 2009:62-69.

13. Charache S, Dover GJ, Moore RD, et al. Hydroxyurea: effects on hemoglobin F production in patients with sickle cell anemia. Blood. 1992; 79(10):2555-2565. [PubMed: 1375104]

14. Ware RE. Helms RW for the SWiTCH Investigators. Stroke With Transfusions Changing to Hydroxyurea (SWiTCH). Blood. 2012; 119(17):3925-3932. [PubMed: 22318199]

15. Schultz WH, Ware RE. Malignancy in sickle cell disease. Am J Hematol. 2003; 74(4):249-253. [PubMed: 14635205] 
16. Ballas SK, McCarthy WF, Guo N, et al. Exposure to hydroxyurea and pregnancy outcomes in patients with sickle cell anemia. J Natl Med Assoc. 2009; 101(10):1046-1051. [PubMed: 19860305]

17. Steinberg MH, McCarthy WF, Castro O, et al. The risks and benefits of long-term use of hydroxyurea in sickle cell anemia: a 17. 5 year follow-up. Am J Hematol. 2010; 85(6):403-408. [PubMed: 20513116]

18. Voskaridou E, Christoulas D, Bilalis A, et al. The effect of prolonged administration of hydroxyurea on morbidity and mortality in adult patients with sickle cell syndromes: results of a 17-year, single-center trial (LaSHS). Blood. 2010; 115(12):2354-2363. [PubMed: 19903897]

19. Weatherall DJ. The inherited diseases of hemoglobin are an emerging global health burden. Blood. 2010; 115(22):4331-4336. [PubMed: 20233970]

20. Ware RE, Despotovic JM, Mortier NA, et al. Pharmacokinetics, pharmacodynamics, and pharmacogenetics of hydroxyurea treatment for children with sickle cell anemia. Blood. 2011; 118(18):4985-4991. [PubMed: 21876119]

21. McGann PT, Ware RE. Hydroxyurea for sickle cell anemia: What have we learned and what questions still remain? Curr Opin Hematol. 2011; 18(3):158-165. [PubMed: 21372708] 

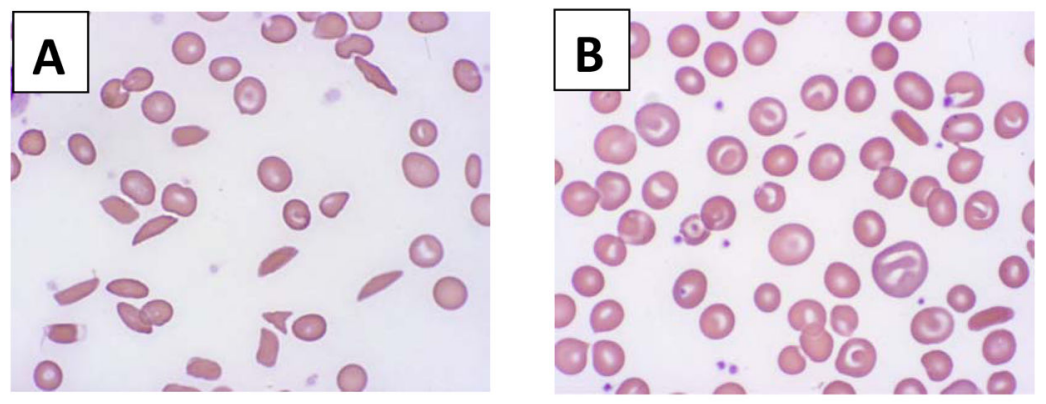

Figure 1.

Peripheral blood smear morphology in sickle cell anemia and response to hydroxyurea therapy. Panel A illustrates a representative pre-treatment blood smear, with evidence of anemia and marked poikilocytosis, including numerous elongated sickled forms. Panel B illustrates a representative on-treatment blood smear at hydroxyurea MTD, with less anemia and reduced poikilocytosis; most cells are macrocytes (without polychromasia) and target cells rather than sickled forms. 


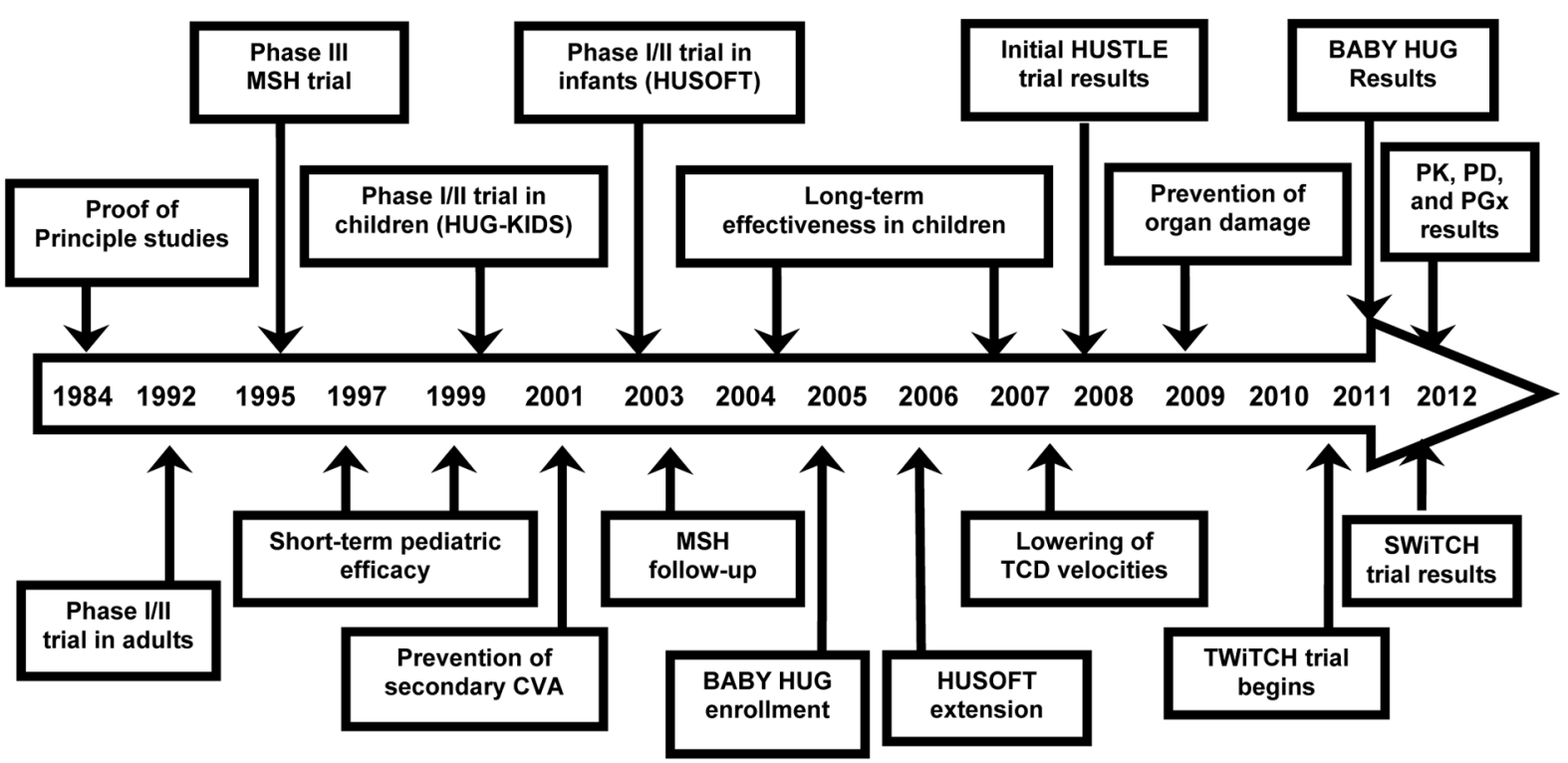

Figure 2.

Timeline of hydroxyurea research for sickle cell anemia. 


\section{Table 1}

Clinical and laboratory indications for considering hydroxyurea therapy in children with sickle cell anemia.

Clinical
Painful episodes
Dactylitis
Acute Chest Syndrome
Laboratory
Severe anemia
Low HbF
High White Blood Cell count
Elevated LDH
Organ dysfunction
Hypoxemia
Proteinuria
Elevated transcranial Doppler (TCD) velocities
Cerebrovascular disease
Miscellaneous
Poor growth and development
Sibling on therapy
Parental request

